\title{
What colour are you? Smartphone addiction traffic lights and user profiles
}

\author{
Sonia San-Martín and Nadia Jiménez \\ Universidad de Burgos, Burgos, Spain
}

\begin{abstract}
Purpose - The key concern nowadays is smartphone addiction and user profiles. Following the risk and protective factors framework, the authors aim to characterize smartphone users according to two levels: (1) individual: referred to the use (i.e. boredom proneness, compulsive app downloading smartphone addiction) and (2) microsystem: referred to family and peers (i.e. family harmony and phubbing). Besides, the authors will derive useful managerial implications and strategies.

Design/methodology/approach - First, an extensive literature revision and in-depth interviews with experts were employed to identify the addiction-related variables at the individual and microsystem level. Second, information was collected from a sample of 275 Spanish smartphone users, and a K-means clustering algorithm was employed to classify smartphone users.

Findings - The proposed traffic lights schema identifies three users' profiles (red, yellow and green) regarding their smartphone addiction and considering individual and microsystem critical variables.

Originality/value - This study proposes a practical and pioneer traffic lights schema to classify smartphone users and facilitate each cluster's strategies development.
\end{abstract}

Keywords Smartphone addiction, Compulsive app downloading, Phubbing, Family harmony, Boredom proneness, Profiles, Cluster

Paper type Research paper

\section{Introduction}

Currently, the smartphone is becoming an indispensable device for people's daily activities and functions. There are 3.5 billion smartphone users globally, representing $44.9 \%$ of the world population (Statista, 2020). 94\% of the young (18-29-year-olds) world population own a smartphone (Turner, 2020). An average smartphone user spends $3 \mathrm{~h}$ per day on their smartphone and checks it 63 times a day (Milijic, 2019; Turner, 2020). During the first half of 2020 , first-time app downloads grew up $28.8 \%$, and consumers spent $\$ 26.4$ billion in the global app ecosystem (Sensortower, 2020). Besides, social media and applications are currently used as a marketing channel (Rita et al., 2021), which involves a challenge to satisfactorily and ethically address users of technologies.

Smartphones are, in fact, critical devices for the world population to the point of engendering hitches. Its use is worldwide and involves calling, texting, using an application (app), reading news, checking social networking, handing e-mail, listening to music, watching TV or gaming (Busch and McCarthy, 2021). Besides, in specific moments such as in quarantines (i.e. due to COVID-19), smartphone usage has increased for shopping or attending classes (Sensortower, 2020). In this context, the COVID-19 crisis could be leading people to smartphone addiction since time spent connected to smartphones has increased on average

(C) Sonia San-Martín and Nadia Jiménez. Published by Emerald Publishing Limited. This article is published under the Creative Commons Attribution (CC BY 4.0) licence. Anyone may reproduce, distribute, translate and create derivative works of this article (for both commercial and non-commercial purposes), subject to full attribution to the original publication and authors. The full terms of this licence

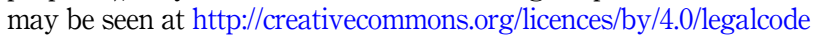

The authors are grateful to funding by the European Comission, under an Erasmus + project with reference 2019-1-ES01-KA201-064250.

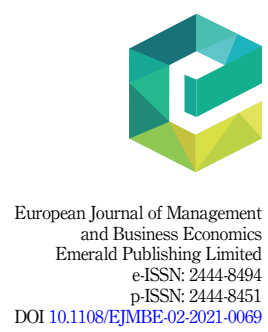

Received 24 February 2021

Revised 19 August 2021

Accepted 18 October 2021 
one hour per day due to lockdowns (Smartme Analytics, 2020). Consequently, the COVID-19 crisis is added to the circumstances that can aggravate the smartphone addiction problem.

Smartphone addiction has attracted the interest of several researchers who have analysed it in different disciplines such as education or health (e.g. Yang et al., 2019; Mahapatra, 2019). Nowadays, addiction is not just related to substance abuse, but it is also related to Internet or smartphone overuse (Kwon et al., 2013), and it implies a challenge for society, education, and business managers. However, an agreed smartphone user classification according to addiction levels and risks and protective factors and corresponding practical recommendations is lacking; it is crucial to derive managerial strategies to address each cluster. One exception is Kiss et al. (2020), who identified four users' profiles according to their digital devices usage.

The risk and protective factors framework (Jessor, 1992) within the social-ecological approach by Bronfenbrenner (2002) applied to study behavioural disorders (such as smartphone addiction), helps to understand complex interactions between inter- and intraindividual factors (Hong and Garbarino, 2012). In this sense, this paper seeks to propose an innovative traffic lights schema to classify smartphone users according to crucial risk (boredom proneness, addiction and compulsive app downloading and phubbing) and protective factors (family harmony) at individual and microsystem levels. The final aim is to derive practical strategies and recommendations for companies involved. Two research questions are proposed:

RQ1. Are there (and how many) different clusters of smartphone users according to risk and protective factors?

RQ2. What social and managerial challenges and implications can be derived from current smartphone use and users?

These findings will enrich existing knowledge through the following contributions: offering an easily understood classification of smartphone user profiles to derive strategies and face addiction levels, using individual and microsystem behavioural variables that involve risk and protective ways facing addiction. To the best of our knowledge, this is the first academic study with a recent broad sample of Spanish smartphone users and proposing business strategies for each clusterwith experts' help.

\section{Smartphone addiction, user profiles, individual and microsystem level variables}

2.1 Smartphone addiction and user profiles

Smartphone addiction can be regarded as "excessive use of smartphones in a way that is difficult to control and whose influence negatively extends to other life fields" (Gökçearslan et al., 2018, p. 640). The World Health Organization has not still recognized smartphone addiction as such. There is some agreement regarding the fact that mobile addiction involves excessive or problematic smartphone use, and it is broadly understood as a behavioural addiction (Yen et al., 2009; Billieux et al., 2008; Mahapatra, 2019). Researchers have addressed the issue of smartphone addiction (Roberts et al., 2015; Lian and You, 2017), and others prefer to speak about mobile phone dependence (Seo et al., 2015) or problematic smartphone use (Busch and McCarthy, 2021; Elhai et al., 2016). Some authors state that individuals are not really addicted to the smartphone device but functions supplied by the device and applications (apps) (Sha et al., 2019). Mobile ubiquity has led to better access to information, increased connectedness and several conveniences that also increase smartphone usage (Handa and Ahuja, 2020).

As for the smartphone user profiles, there are few recent studies considering clustering for this kind of addiction. While there is more literature on Internet addiction user profiles, smartphone user profiles lack the extent of our knowledge. Moreover, some studies only distinguish addicts vs non-addicts (e.g. Shu and Chieh-Ju, 2007). Vaghefi and Lapointe (2016) 
classified individuals into five types (i.e. addicts, fanatics, highly engaged, regular and thoughtful users), considering their dependence and self-regulation regarding smartphone use, their information technology addiction and liability to addiction. Kayri and Günüç (2016) also offered a typology according to Internet addiction and socioeconomic level and found three clusters (i.e. no addiction, risk of addiction and addiction).

To develop a set of profiles that would capture students' addiction to digital devices and their usage relative to risk, Kiss et al. (2020) identified four distinct user profiles through cluster analysis. The first cluster was labelled as strongly protected sensation-seekers who were more prone to problematic use with moderately high protection levels but with the highest scores on the boredom proneness and sensation-seeking scales. The second cluster consisted of more balanced and non-vulnerable users, who achieved average scores on both risk and protective factors scales. The third cluster was labelled protected, conscious users prone to problematic use with lower levels of problematic use and risk factors and higher protective factors levels. The fourth cluster was labelled as strongly problematic, unprotected users, who achieved the highest scores of problematic use, and they were the less protected and had the lowest protective factors scores.

\subsection{The risk and protective factors framework and addiction-related variables at the individual and microsystem level}

The risk and protective factors framework provides a theoretical background for researching problematic behaviours among youth (Jessor, 1992). This framework, employed initially on medicine and psychiatric research (O'Connell et al., 2009), applies a socio-psychological and epidemiological perspective to explain the whole complex of personal, social and other environmental factors that can explain and even prevent behavioural disorders amongst youngsters (Jessor, 1992).

A later approach to this framework (i.e. social-ecological approach) suggests that four contextual domains help determine predictors of behavioural problems and addictions (Bronfenbrenner, 2002). These four domains are recalled by Hong and Garbarino (2012) as personal level (individual), microsystem level (family and peers), exosystem level (community) and macrosystem level (societal). The personal level refers to individual youth characteristics (i.e. psychological characteristics). The microsystem level refers to the individual direct environment (e.g. home) and comprises interpersonal relationships. Thus, at this level, family, school and compeers are the primary microsystem elements for youth. In this work, we are going to focus on these two levels as they are where most problems regarding incorrect use of smartphones appear and then are translated to a broader social level (i.e. exosystem and macrosystem levels; not considered in this study).

There are opposing factors in each level that can lead and mitigate the development of some behavioural disorders, called risk and protective factors (Jessor, 1992). A risk (protective) factor is understood as an individual attribute or environmental context that increases (reduces) the possibility of addiction, behavioural problem or disorder (Clayton, 1995). This research focuses on risk and protective factors to classify smartphone users at the individual and microsystem levels. Table 1 shows several factors at the individual level have more incidence to explain smartphone addiction, and studies about the effect of factors at the microsystem are scarce and related to the context in which the individual behaves. The methodology section explains how experts helped us select the most mentioned risk and protective factors.

Next, we are dealing with the factors considered at the individual level (compulsive app downloading and boredom proneness) and at the microsystem level (phubbing and family harmony), taking into account the literature revision and experts' opinions and considering that they can have implications for society and management. 


\section{EJMBE}

\begin{tabular}{|c|c|c|}
\hline Level & Risk & Protective \\
\hline $\begin{array}{l}\text { Personal level } \\
\text { (individual) }\end{array}$ & $\begin{array}{l}\text { - } \quad \text { Fear of missing out (FoMO) (Handa and } \\
\text { - } \quad \text { Bhuja, 2020; Wolniewicz et al., 2020) } \\
\text { - Regan, et al. 2020) } \\
\text { - } \quad \text { Body dissatisfaction (Liu et al., 2020a) } \\
\text { - } \quad \text { Female gender (Choi et al., 2015) } \\
\text { - } \quad \text { Alcohol use (Choi et al., 2015) } \\
\text { - } \quad \text { Smoking (Choi et al., 2015) } \\
\text { - } \quad \text { Anxiety (Choi et al., 2015) } \\
\text { - } \quad \text { Depression (Choi et al., 2015) } \\
\text { - Impulsivity (Regan } \text { et al. } 2020) \\
\text { - } \quad \text { Nomophobia (Regan et al. 2020) }\end{array}$ & $\begin{array}{l}\text { - } \quad \text { Resilience (Choi et al., 2015; Kiss } \\
\text { et al. 2020) } \\
\text { - Self-control (Kim et al., 2018; Ekşi } \\
\text { et al., 2020; Kiss et al. 2020) } \\
\text { - Self-esteem (Kiss et al., 2020) } \\
\text { - } \quad \text { Character strengths (Choi et al., } \\
\text { 2015) } \\
\text { - Mindfulness (Regan, et al. 2020) } \\
\text { - Conscientiousness (Lian and You, } \\
\text { - } 2017 \text { Virtues (Lian and You, 2017) }\end{array}$ \\
\hline $\begin{array}{l}\text { Microsystem level } \\
\text { (family and peers) }\end{array}$ & $\begin{array}{l}\text { - } \quad \text { Being phubbed (Chotpitayasunondh } \\
\text { - } \quad \text { parental neglect (Kwak et al., 2018) } \\
\text { - } \quad \text { Domestic violence (Jeong et al., 2020) } \\
\text { - } \quad \text { Family dysfunction (Liu et al., 2020b) }\end{array}$ & $\begin{array}{l}\text { - Family harmony (Kim et al., 2018; } \\
\text { Ekşi et al., 2020) } \\
\text { - Parent-child attachment (Xie et al., } \\
\text { 2019) } \\
\text { - Teacher support (Jeong et al., 2020) }\end{array}$ \\
\hline
\end{tabular}

Table 1.

Risk and protective

factors of smartphone addiction
2.2.1 Individual level: compulsive downloading and boredom proneness. 2.2.1.1 Compulsive downloading. Younger users are predisposed to compulsive phone usage. Okazaki et al. (2019, p. 2) highlight that compulsive technology-related uses and "compulsive buying have become an important societal issue that needs to receive more attention from social marketers and policymakers". Notwithstanding, research suggests that smartphone addictive behaviours are closely associated with other behavioural disorders (Pourrazavi et al., 2014). Parylak et al. (2011) propose that smartphones also incite some compulsive behaviour regarding the technology sphere. Following Hsiao (2017, p. 276), compulsive app downloading could be understood as "the individual's lack of control over [downloading] mobile app and the tendency to spend too much time and effort on mobile apps". This concept is novel, since to the best of our knowledge, compulsive buying literature has not spoken about compulsive "buying" [downloading] of apps since there is an abundance of free app version in the apps' market (Tang et al., 2019). Compulsiveness involves the consumer propensity to impetuous, non-reflexive, immediate and kinetical app download (Rook and Fisher, 1995; Altintas et al., 2010). This behaviour could respond to the individuals' inability to control a desire triggered by smartphone addiction symptoms (Altintas et al., 2010). Compulsive app downloading could reflect compulsion and, a ritual answer to uncontrolled thoughts about obtaining products [apps] (Okazaki et al., 2019, p. 3) that might be due to smartphone addiction and which involves a challenge for businesses that develop apps and want to be socially responsible (Mrad and Chi Cui, 2020).

2.2.1.2 Boredom proneness. As Kiss et al. (2020) state, psychological factors, such as boredom, serve as useful tools for providing information to better understanding the role of risk factors when dealing with the youth's problematic use of digital devices. Wolniewicz et al. (2020) consider boredom proneness a trait-based tendency to experience a lack of interest, indifference or apathy. Individuals who experience high levels of leisure boredom may engage in deviant activities such as substance use (Leung, 2007). Kiss et al. (2020) has suggested that having an abundance of time is central to boredom. Leisure boredom might be related to other forms of addiction and has been implicated in deviant activity involvement, particularly drug use and delinquency. Increasingly, the cell phone allows adolescents, while having not much to do, to be engaged in several activities, such as texting in SMS, gaming, shopping, accessing the Internet, reading online news, shooting and viewing pictures or 
video, among others. Not surprisingly, literature found that the higher the level of boredom a person experiences, the higher the likelihood of being dependent on the smartphone (Leung, 2007), recycling and clothing disposal (Kwon et al., 2020) and shopping impulsively (Sundstrom et al., 2019; Bozaci, 2020).

2.2.2 Microsystem level: phubbing and family harmony. 2.2.2.1 Phubbing. Phubbing is the act of ignoring someone by using the smartphone instead of interacting face-to-face with others (Chotpitayasunondh and Douglas, 2016). "The person engaging with a smartphone instead of paying attention to another person or persons during social interaction is called a phubber, while the person(s) who is/are being phubbed, that is, phone snubbed, during the social interaction is called the "'phubbee(s)" (Al-Saggaf and O'Donnell, 2019, p. 132). When someone is phubbed, he/she reports less trust in the phubber, a decreased perceived quality of communication and diminished satisfaction with the relationship (Chotpitayasunondh and Douglas, 2016). Phubbing is considered an irritating and impolite act (Miller-Ott and Kelly, 2017) and, people who have been phubbed described strategies to evade face-to-face lost contact. Sometimes this action (phubbing) is used to compensate for the related needs and avoid the sense of social exclusion (David and Roberts, 2017). Xie et al. (2019) find that individuals' mobile phone addiction suffers intensification after facing phubbing. Existing research on phubbing highlighted several factors that could cause one to use their smartphone while having a face-to-face conversation with others, including smartphone addiction, SMS (texting) addiction, social media addiction, Internet addiction and to some extent, game addiction (Wolniewicz et al., 2020). Phubbing can also affect concentration and relations among education stakeholders when the mobile device is used for non-academic purposes (Hall-Newton et al., 2019).

2.2.2.2 Family harmony. Regarding the microsystem level, the family environment is related to several behavioural problems, including problematic smartphone use (O'Connell, 2009; Altintas et al., 2010; Busch and McCarthy, 2021). Family harmony plays a role against the development of psychopathology and represents a resource to face life stress (Kavikondala et al., 2016). Family harmony is defined as "a value that expresses the closeness, cooperation, and relationships among family members and contributes to the individuals' well being" (Ekşi et al., 2020, p. 3).

Buctot et al. (2020) affirm that individuals that show smartphone addiction also show a problematic relationship with family mainly due to users' diverted attention, and they try to hide their abusive use from family. Thus, the youth's family background is crucial in determining youth's behaviour regarding smartphone use (Buctot et al., 2020). Family models and norms influence the development of addictions and, not receiving open and mutual communication with the family or close support negatively affect youth's behaviour (Yen et al., 2007; Kavikondala et al., 2016) and exacerbate the problematic technology use (Ekşi et al., 2020) and affect learning good or bad consumption habits (Scholderer and Grunert, 2001; Kleinschager and Morrison, 2014; Essiz and Mandrik, 2021). Moreover, Dinc (2015) suggests that an intimate atmosphere where youths often see their family members using smartphones contributes to smartphones' extensive use amongst youngsters. Lee and Lee (2017) found that parental attachment is negatively associated with smartphone use addictive tendency, acting protectively.

\section{Methodology}

\subsection{Study sample and measures}

The selected sample comprised Spanish smartphone users. Although $44.9 \%$ of the world population owns a smartphone (Statista, 2020), this percentage is much higher in Spain $(74.3 \%)$. Spain was the European country with the highest penetration of smartphones. Spain occupies the fifth position in 10 countries ranking with higher smartphone usage 
(Turner, 2020). According to a recent report, 45.3\% of young Spaniards between 18 and 24 years old declare themselves addicted to their smartphone (Rastreator, 2019). It reflects that $25.6 \%$ of the Spanish population consider mobile addicts, and $77.3 \%$ affirm they could not live without a smartphone.

Following our purpose of identifying types of smartphone users regarding their risk to become smartphone addicts, we employed a targeted non-probability sampling method with Prolific platform (i.e. 18-25-year-olds, resident in Spain and gender-balanced sample). Prolific is a crowdsourcing website (http://www.prolific.ac) supported by the University of Oxford that allows collecting data via online surveys. Participants were offered compensation of $€ 2.23$ for filling the survey. 275 valid questionnaires were obtained, with a response rate of $91.6 \%$. The sample profile is slightly predominantly masculine $(58.1 \%)$, between 18 and 22 years old $(66.9 \%)$, studying university degrees $(66.5 \%)$ and spending an average of 4.94 (SD: 3.28) hour per day using their smartphone. According to the secondary data available about the Spanish youth population smartphone use and addiction, the sample profile and the national profile are similar. $46.7 \%$ of the young Spanish males between 16 and 25 years old ( $41 \%$ ) with middle and high education $(93.9 \%)$ spent daily using their smartphone an average of 3.5 h (De-Sola et al., 2019; Ditrendia, 2019).

As previously said and apart from literature revision, in-depth interviews lasting an average of one hour following a semi-structured questionnaire were maintained with six experts on addiction and smartphone use. Experts from different disciplines (management, marketing, psychology, sociology and education) help us to confirm the main risk and protective behavioural factors causing addiction and included in individual and microsystem levels. The interview was divided into three key open questions with the purpose to (1) list the risk and protective behavioural factors related to smartphone addiction; (2) classify factors on individual and microsystem level; and (3) suggest some smartphone addiction profiles. After obtaining the interviews information, a hybrid thematic analysis was followed for coding (Fereday and Muir-Cochrane, 2006). This approach integrates data-driven inductive coding with theory-based deductive coding. We employ the Atlas.TI qualitative software and two researchers analysed the transcripts independently and subsequently compared their findings. Areas of disagreement were resolved by discussion. The open question related to the most critical variables that can enhance smartphone addiction shows that boredom, phubbing and compulsive behaviour were the most mentioned variables. The critical factor preventing addiction was a unanimous answer related to family (i.e. communication among family, family norms or family environment), considered in the validated family harmony concept.

Later on, prior literature was employed to develop the survey instrument. Smartphone addiction was measured using the SAS short-scale validated by López-Fernández (2017), boredom proneness was measured with the scale employed by Al-Saggaf et al. (2019), family harmony with the scale of Kavikondala et al. (2016), phubbing using the scale from Franchina et al. (2018) and compulsive downloading adapting the scale used by Okazaki et al. (2019). We use five-point Likert scales from strongly disagree (1) to agree strongly (5).

\subsection{Data analyses}

Data analyses were conducted using IBM SPSS statistics 26 and LISREL 8.7. First, the exploratory factor analysis (EFA) was run to test constructs unidimensionality. The varimax rotation revealed that the five studied constructs have eigenvalues higher than 1 and a total explained variance of $55.14 \%$. At this stage, Harman's single-factor test was employed to address CMB's issue (Malhotra et al., 2006). Attending Fuller et al. (2016), Harman's test suggests a problem with $\mathrm{CMB}$ if the first factor accumulates more than $50 \%$ of the variance. The exploratory factor analysis loaded with all of the items onto one factor shows that a unique unrotated factor explained $20.2 \%$ of the data variance. Thus, we discard CMB problems. 
Second, a confirmatory factor analysis (CFA) revealed the measurement model convergent and discriminant validity. The results of the adjusted and re-specified model are shown in Tables 2 and 3. Three items were suppressed since they did not show the required standards to be considered reliable and valid following Bagozzi and Yi (2012). The reliability of the final scales was corroborated with the values of the alpha Cronbach's coefficient $(>0.7)$, the coefficient of composite reliability $(>0.6)$ and average variance extracted $(>0.5)$ (Bagozzi and Yi, 2012) (see Table 2). Regarding the discriminant validity of the constructs, the results show that the root of the variance extracted in all cases is larger than the correlations between constructs (Farrell, 2010) (see Table 3). The measurement model shows an acceptable fit: a $\chi^{2}$ (df: 372$)$ of $703.8(p=0.00)$, a comparative fit index (CFI) of 0.93 and a root mean square error of approximation (RMSEA) of 0.05 .

In the following section 4, results are explained.

\section{Results}

\subsection{Cluster analysis}

As previous authors have recently performed (Kiss et al., 2020) in smartphone addicts, we run a K-means clustering algorithm to classify smartphone users into different groups depending on their smartphone addiction and individual and microsystem levels related factors. We used the five-factor punctuations (F1: Smartphone addiction; F2: Boredom proneness; F3: Family harmony; F4: Phubbing; F5: Compulsive app downloading) formerly validated as input variables. The $K$-means clustering algorithm requires, as an input, the number of output clusters to produce. To reduce the possible optimal number of clusters, we run the analysis based on our understanding of how smartphone addicts have been classified in the past $(N=2$ to $N=5$ ) (Shu and Chieh-Ju, 2007; Vaghefi and Lapointe, 2016; Kayri and Günüç, 2016; Kiss et al., 2020). The number of clusters that offers better results was $K=3$, attending the group size, the degree of significance of each factor, and the final centre values (FCV).

Furthermore, attending Punj and Stewart (1983), Kodinariya and Makwana (2013) and Krzanowski and Lai (1988) recommendations, the model selection of the optimal number of clusters was implemented in two phases. We followed the standard practice of generating all possible classifications in the first phase, ranging from $K=N$ to $K=1$. Then, we compare the set of candidate models quality criterion by two-steps cluster analysis employing SPSS. In the second phase, we select the most appropriate model based on Akaike's Information Criterion (AIC). Figure 1 displays a graph showing how the curve has an elbow that nearly flattens after $k$ equals three, thus corroborating $K=3$ as the optimal number of clusters.

The analysis of variance (ANOVA) corroborates that the five factors (F1 to F5) are significant at a level of $95 \%$ to characterize the groups. The $F$-statistic values indicate that family harmony and phubbing behaviour produce the most extensive and smallest variations between groups. Table 4 shows the ANOVA analysis results and three conglomerates information.

The depth interviews with experts disclose that they consider helpful the employment of the traffic lights schema proposed by us as researchers. They consider colours (red, yellow and green) useful to classify smartphone users by their risk to develop smartphone addiction for two reasons: (1) it is a universal language of signals across different countries and (2) it is an easy way for the user to identify the risk to become smartphone addict regardless any personal characteristic. Also, the traffic light schema of three colours (green, yellow and red) perfectly matches the number of groups found by this research (3). Thus, each colour will be described attending their punctuation of the risk and protective factors going from green (low risk of smartphone addiction), to yellow (middle risk of smartphone addiction) to red (high risk of smartphone addiction). The following description attends to the information displayed in Table 4. 
EJMBE

Table 2.

Descriptive statistics, EFA and CFA results

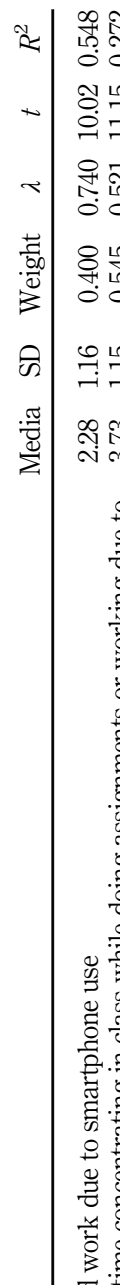

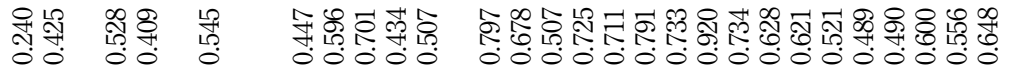

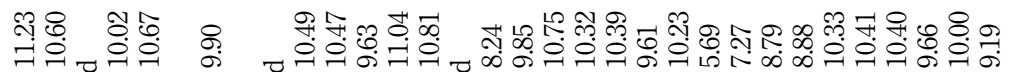

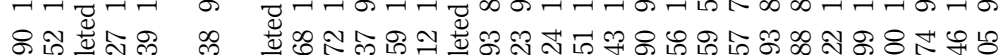

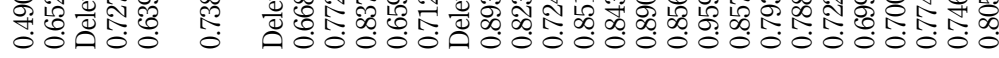

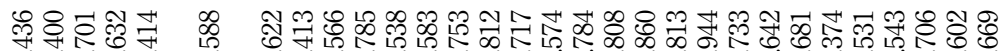
○

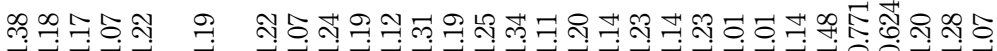

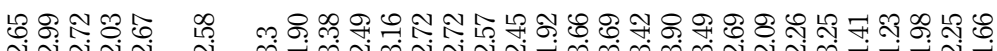
范 阱点

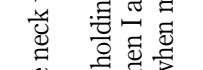
Ð

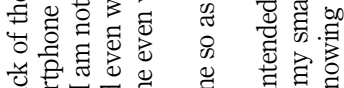

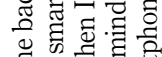

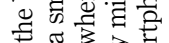

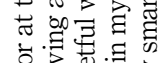

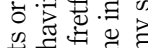

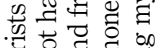

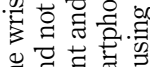

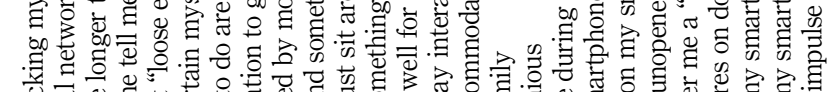

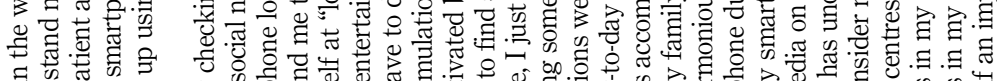

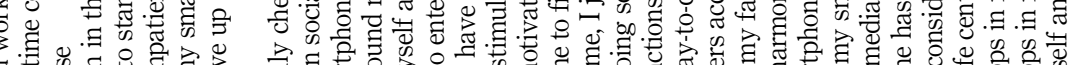

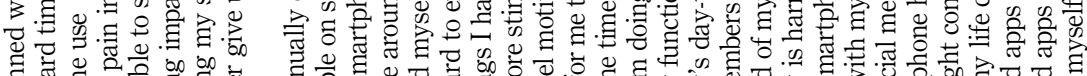

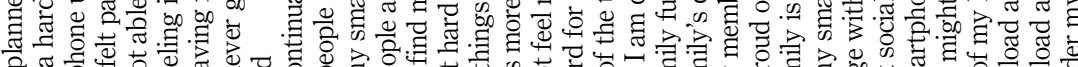

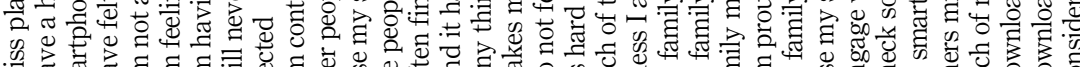

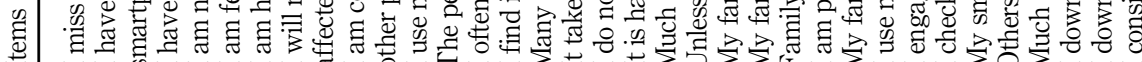

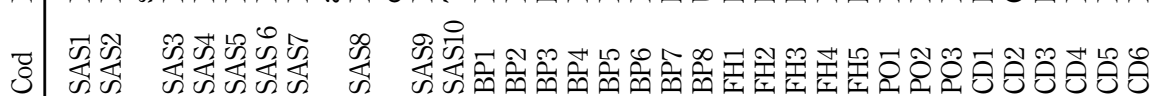
范过 :웡 烏 递灾 을

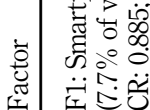

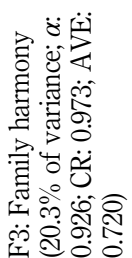

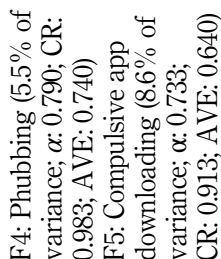


Cluster 1: green smartphone users. Smartphone users included in this first cluster show higher positive scores in family harmony $(\mathrm{FCV}=0.59237)$ and the higher negative punctuation in smartphone addiction $(\mathrm{FCV}=-0.38367)$ and also in other factors [boredom proneness $(\mathrm{FCV}=-0.58406)$, phubbing behaviour $(\mathrm{FCV}=-0.35244)$ and compulsive downloading (FCV $=-0.42467)]$ than other groups. This description could fit with smartphone user that are not at risk of developing smartphone addiction. These punctuations

\begin{tabular}{lrrrrr}
\hline & F1 & F2 & F3 & F4 & F5 \\
\hline F1 & 0.707 & & & & \\
F2 & 0.597 & 0.821 & & & \\
F3 & -0.171 & -0.313 & 0.848 & & \\
F4 & 0.701 & 0.515 & -0.127 & 0.858 & 0.799 \\
F5 & 0.679 & 0.611 & -0.177 & 0.646 & .
\end{tabular}

Note(s): Values below the diagonal show correlations between constructs, values on the diagonal (in italic) show the square root of AVE. F1: Smartphone addiction; F2: Boredom Proneness; F3: Family harmony; F4: Phubbing; F5: Compulsive app downloading

Table 3.

Discriminant validity matrix

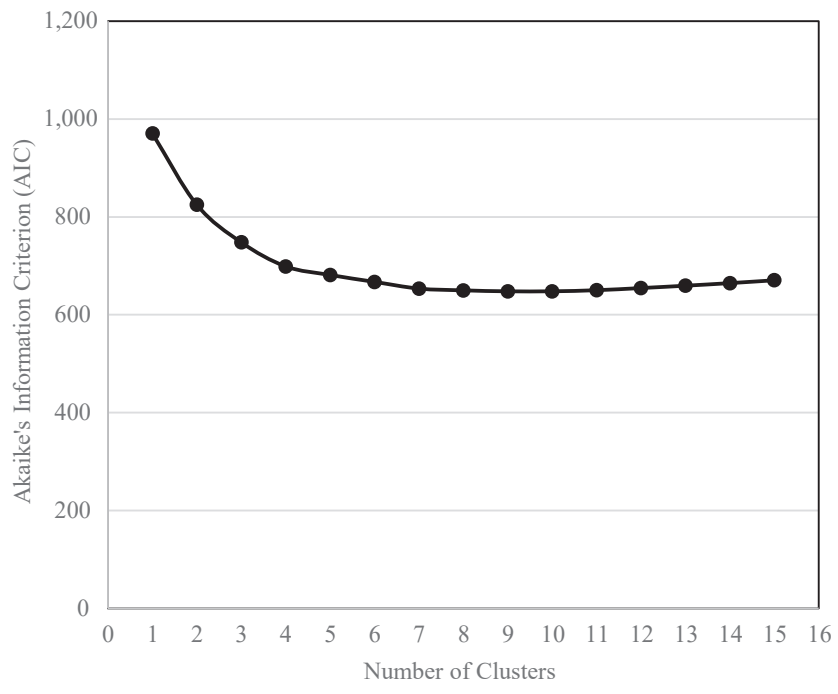

Figure 1.

Number of clusters vs. AIC criterion

\begin{tabular}{|c|c|c|c|c|c|c|c|c|c|}
\hline \multirow[b]{2}{*}{ Factor } & \multirow[b]{2}{*}{$F$} & \multicolumn{5}{|c|}{ Final centre value (FCV) } & \multicolumn{3}{|c|}{ Distance from conglomerate centres } \\
\hline & & $\begin{array}{l}\text { Sig. } \\
(95 \%)\end{array}$ & Green & Red & Yellow & & $\begin{array}{c}\text { Green } \\
(n=125)\end{array}$ & $\begin{array}{c}\text { Red } \\
(n=81)\end{array}$ & $\begin{array}{c}\text { Yellow } \\
(n=69)\end{array}$ \\
\hline $\mathrm{F} 1$ & 58.03 & 0.000 & -0.3837 & 0.8430 & -0.2946 & Green & & 2.62 & 1.97 \\
\hline $\mathrm{F} 2$ & 66.39 & 0.000 & -0.5841 & 0.7446 & 0.1840 & & & & \\
\hline F3 & 156.45 & 0.000 & 0.5924 & 0.1193 & $-1,213$ & Red & 2.62 & & 2.57 \\
\hline $\mathrm{F} 4$ & 56.77 & 0.000 & -0.3524 & 0.8383 & -0.3456 & & & & \\
\hline F5 & 88.87 & 0.000 & -0.4247 & 0.9705 & -0.3700 & Yellow & 1.97 & 2.57 & \\
\hline
\end{tabular}

Note(s): F1: Smartphone addiction; F2: Boredom Proneness; F3: Family harmony; F4: Phubbing; F5: Compulsive app downloading

Table 4.

ANOVA results and conglomerates information 
reveal that smartphone users in this first cluster tend to be embedded in a family framework where harmony stands out. This family characteristic may prevent these users from developing smartphone addiction, boredom, phubbing others and compulsive downloading. This group represents $45.5 \%$ of the total sample.

Cluster 2: red smartphone users. The second cluster includes people who show higher positive punctuations in smartphone addiction $(\mathrm{FCV}=0.84299)$, boredom proneness $(\mathrm{FCV}=0.74456)$, phubbing behaviour $(\mathrm{FCV}=0.83829)$ and compulsive downloading $(\mathrm{FCV}=0.97052)$. This description corresponds to a smartphone user type that in fact, are addicted. Red smartphone users tend to quickly get bored, phub others by using their smartphone, download apps compulsively, and be considered addicts to smartphone use. This group represents $29.5 \%$ of the total sample.

Cluster 3: yellow smartphone users. The smartphone users included in this third cluster show higher negative punctuations in family harmony $(\mathrm{FCV}=-1.21324)$. This punctuation could place the users in this cluster at a medium risk of developing smartphone addiction since their family framework might not protect them from this behavioural disorder. These users' punctuations also disclose that yellow smartphone users are prone to be bored $(\mathrm{FCV}=0.18403)$, and it seems that this could be the open door to engage with the smartphone. This group represents the smallest group and represents $25 \%$ of the total sample. Although they are not addicted at this moment $(\mathrm{FCV}=-0.29455)$, and they do not show dangerous behaviours such as compulsive app downloading, we consider they are at risk of addiction.

\subsection{Clusters' demographic and smartphone use characterization}

The information of the final centre values for each of the three clusters concerning the five factors (Table 4) facilitates describing differences between clusters and characterizing them considering different smartphone users' individualities (Table 5). Table 5 displays data that reveal the frequency of each group studied features and statistical post-hoc tests (Chi-square and ANOVA test) to discard or appreciate differences among groups regarding sample characteristics and smartphone usage (Pallant, 2001).

Specifically, it offers information about their demographic and socioeconomic characteristics of gender, education, average school performance and the age when receiving the first smartphone. Attending prior literature, different profiles of smartphone use could be identified in the function of the employed characteristics (i.e. gender, education, academic performance and age) (Busch and McCarthy, 2021). In addition, the daily media usage time via mobile and the number of downloaded apps are two objective variables related to smartphone addiction that are also mentioned as relevant to characterize smartphone addicts in previous studies (Noe et al., 2019). Also, it is hard to ignore the situation of the pandemic that we live in nowadays, which may raise smartphone use (Smartme Analytics, 2020). Thus, we decide to include this variable too.

Thus, Table 5 displays in the first three rows the proportion of three sample characteristics (i.e. gender, education and rise in smartphone use during COVID-19 crisis) in the function of the cluster of membership. The education and the rise in smartphone use during COVID-19 crisis are the two characteristics that show significant differences between smartphone users profiles proportions attending the Chi-square test (Pallant, 2001). The third, fourth, fifth and sixth rows show four objective sample characteristics (i.e. age, daily media usage time via mobile, number of downloaded apps and average school performance) regarding the proportion of each cluster. The age, daily media usage time via mobile and the number of downloaded apps are the three objective characteristics that show significant differences between smartphone users attending the ANOVA test developed (Pallant, 2001). The difference between smartphone users' profiles attending their demographic and smartphone use characteristics is detailed in the following epigraph. 


\begin{tabular}{|c|c|c|c|c|c|c|}
\hline \multicolumn{2}{|c|}{ Sample characteristics } & $\begin{array}{c}\text { Green } \\
\text { smartphone } \\
\text { users }\end{array}$ & $\begin{array}{l}\text { centage per clu } \\
\text { Red } \\
\text { smartphone } \\
\text { users }\end{array}$ & $\begin{array}{c}\text { Yellow } \\
\text { smartphone } \\
\text { users }\end{array}$ & $\begin{array}{l}\chi^{2} \text { Pearson } \\
\text { (sig.) }\end{array}$ & \multirow{2}{*}{ colour are you? } \\
\hline \multirow[t]{2}{*}{ Gender } & Male & 59.2 & 60.5 & 54.4 & $3.7(0.460)$ & \\
\hline & Female & 40.8 & 39.5 & 45.6 & & \\
\hline \multirow[t]{6}{*}{ Education } & Secondary school & 0.8 & 3.7 & 0.0 & $26.0^{* *}(0.004)$ & \\
\hline & High school & 5.7 & 13.6 & 2.9 & & \\
\hline & Vocational school & 4.1 & 17.3 & 16.2 & & \\
\hline & University degree & 74.0 & 56.8 & 64.7 & & \\
\hline & Postgraduate/PhD & 2.4 & 0.0 & 1.5 & & \\
\hline & Not studying & 13.0 & 8.6 & 14.7 & & \\
\hline Rise in & No increase & 31.2 & 16.0 & 23.2 & $22.3^{* *}(0.001)$ & \\
\hline smartphone use & Less than $1 \mathrm{~h}$ & 16.8 & 9.9 & 29.0 & & \\
\hline during Covid-19 & Between 1 and $2 \mathrm{~h}$ & 30.4 & 35.8 & 33.3 & & \\
\hline \multirow[t]{2}{*}{ crisis } & More than $2 \mathrm{~h}$ & 21.6 & 38.3 & 14.5 & & \\
\hline & & $\begin{array}{c}\text { Green } \\
\text { smartphone } \\
\text { users }\end{array}$ & $\begin{array}{c}\sigma(\mathrm{SD}) \\
\text { Red } \\
\text { smartphone } \\
\text { users } \\
\end{array}$ & $\begin{array}{c}\text { Yellow } \\
\text { smartphone } \\
\text { users }\end{array}$ & $F$ (sig.) & \\
\hline \multicolumn{2}{|l|}{ Age } & $21.5(2.12)$ & $20.8(2.26)$ & $21.8(1.99)$ & $4.5^{* * *}(0.012)$ & \\
\hline \multicolumn{2}{|c|}{ Daily media usage time via mobile } & 4.4 (3.14) & $5.9(3.45)$ & $4.8(3.09)$ & $5.9 * *(0.001)$ & \\
\hline \multirow{2}{*}{\multicolumn{2}{|c|}{$\begin{array}{l}\text { Number of downloaded apps } \\
\text { Average school performance }\end{array}$}} & $24.5(25.02)$ & $31.8(36.7)$ & $19.3(15.1)$ & $4.0 * *(0.019)$ & $\begin{array}{l}\text { lable } 5 . \\
\text { Descriptive }\end{array}$ \\
\hline & & $9.1(11.1)$ & $9.9(13.4)$ & $7.8(1.13)$ & $0.821(0.441)$ & information about \\
\hline \multicolumn{6}{|c|}{ Note(s): б: mean; SD: Standard deviation. ** 95\% level of confidence } & clusters \\
\hline
\end{tabular}

\subsection{Cluster descriptions and differences}

This epigraph presents a description of each cluster according to the characteristics that show significant differences between groups (Table 5). Each cluster previously associated with colour regarding their smartphone addiction and considering individual and microsystem critical variables will be characterized by the main features of each profile. This practice of cluster characterization relative to certain sociodemographic and smartphone use variables is well accepted and employed in previous literature (Kiss et al., 2020).

Cluster 1: green smartphone users. This group has a majority of males $(59.2 \%)$ with an average age of 21 and a half. This group has the highest percentage of people studying university degrees $(74 \%)$ in comparison with other groups $\left(\chi^{2}: 26 ; p<0.000\right)$. Regarding their smartphone usage, green smartphone users spend significantly less time using their smartphone in comparison with red users $(6: 1.5 ; p<0.000)$ and yellow users $(6: 0.4 ; p<0.000)$, and this group also has the highest percentage of people $(31.2 \%)$ that do not notice any increase in their smartphone use time during COVID-19 crisis in comparison with other groups $\left(\chi^{2}: 22.3 ; p<0.000\right)$.

Cluster 2: red smartphone users. This cluster includes a large majority of males (60.5\%). They are on average younger than 21 years old, and also, they are significantly younger than green users (б: $0.7 ; p<0.000)$ and than yellow users (б: $1 ; p<0.000)$. This cluster includes a high percentage of individuals studying high or vocational school $(30.9 \%)$ in comparison with other groups $\left(\chi^{2}: 26 ; p<0.000\right)$. Regarding red users' smartphone usage, this group spends significantly more time using their smartphone in comparison with green users (б: 1.5; $p<0.000)$ and yellow users (6: $1.1 ; p<0.000)$. This group reveals to download significantly more apps than green users (б: $7.3 ; p<0.000)$ and than yellow users $(6: 12.5 ; p<0.000$ ). Moreover, a higher percentage $(74.1 \%)$ of individuals in this group affirms that their use of 
smartphone has increased more than $1 \mathrm{~h}$ per day during the COVID-19 crisis in comparison with other groups $\left(\chi^{2}: 26 ; p<0.000\right)$.

Cluster 3: yellow smartphone users. This group includes similar percentages of both genders ( $54.4 \%$ is male, and $45.6 \%$ is female). This third group has a higher percentage of people that affirm not being studying $(14.7 \%)$ in comparison with other groups $\chi^{2}: 26$; $p<0.000)$. Yellow smartphone users are the group that download significantly fewer apps in comparison to green users $(6: 5.2 ; p<0.000)$ and red users $(6: 12.5 ; p<0.000)$. Moreover, this group also has the highest percentage of people $(29 \%)$ that affirm to have boosted their smartphone usage time during the COVID-19 crisis less than $1 \mathrm{~h}$, in comparison with other groups $\left(\chi^{2}: 22.3 ; p<0.000\right)$.

\section{Discussion}

Smartphone addiction constitutes a social and managerial challenge (Mrad and Chi Cui, 2020) and can also be dangerous issue due to overuse, abuse or addiction and doing business. The smartphone has become one of society's most widespread and influential technological innovations (Busch and McCarthy, 2021). This study proposes an easy, innovative schema of smartphone users according to their level of addiction and related variables. Therefore, this paper's main contributions are four: (1) Drawing on multidisciplinary literature and applying a framework from epidemiology to analyse an important social issue with rich managerial practical implications. (2) The proposed traffic lights model use the risk and protective factors framework by considering critical variables at the individual (boredom proneness, compulsive app downloading) and microsystem level (phubbing and family harmony). To the extent of our knowledge, this is one of the first studies that offer a typology of Spanish smartphone users considering risk and protective variables from different disciplines to the extent of our knowledge. (3) The study answers the gap of needed studies with primary smartphone users' information since most existing studies are quickly getting obsolete and are based on Internet addiction and technology uses. In fact, smartphone addiction is changing exponentially every year. For example, the study by Kayri and Günüç (2016) offered a typology according to the level of Internet addiction and found $9 \%$ addicts, while our study shows almost 30\% of addict smartphone users). Finally, (4) it helps policymakers and managers design strategies to address each of the three clusters to overcome smartphone addiction's potential adverse effects and derive recommendations for managers. We have revised the literature and have obtained the help of experts in smartphone use and overuse to offer an easily applicable typology of users (i.e. green, yellow and red smartphone users).

As mobile technology continues growing its popularity, marketing academics and managers, policymakers and society must comprehend the effect that technologies exert on individual behaviours. First, the literature is unclear whether certain constructs can be related and explain smartphone addiction (Busch and McCarthy, 2021). In this sense, the interviews with experts give us clues that disclosed boredom, phubbing, compulsive behaviour and family bond as the most critical variables related to smartphone addiction that could help classify smartphone users. To the extent of our knowledge, only the study by Kiss et al. (2020) classifies smartphone users according to their addiction and other variables, and ours is the first contemplating three groups, which help not only to distinguish addicts (red users) vs non-addicts (green users) but also individuals at risk of addiction (yellow users). Answering RQ1, our study offers a broad classification of smartphone users considering risk and protective factors involved at individual and microsystem levels, and each cluster corresponds to one colour of a called traffic-lights schema (i.e. green, red and yellow). In this sense, green users fit with smartphone users that are not at risk of developing smartphone addiction (this first cluster mainly shows higher positive scores in family harmony and higher negative punctuation in smartphone addiction than other groups). Red users comprise 
individuals who tend to get bored quickly, phub others by using their smartphone, download apps compulsively and be considered addicts to smartphone use (this second cluster includes people who show higher positive punctuations in smartphone addiction, boredom proneness, phubbing behaviour and compulsive downloading). Finally, yellow users are the ones who are not addicted at this moment, but they are at risk of addiction (this third cluster shows higher negative punctuations in family harmony, although they are not addicted at this moment, they are prone to get bored, and it seems that this could be the open-door to engage with the smartphone addiction). Precisely, our results show that the construct of family harmony is the most relevant - one of the factors we have studied here - when addressing addiction and explaining different smartphone user behaviours, as Buctot et al. (2020) suggest. Boredom proneness and compulsive app downloading also help classify individuals into a group of less or more risk of addiction, as they have been identified as essential variables when dealing with smartphone overuse and dependence (Leung, 2007; Parylak et al., 2011).

With these results in mind and together with experts' in-depth insights and with the aim of addressing RQ2, some proposed strategies for each group can be the following. In the case of green smartphone users, the primary strategy should be to reinforce family bonds since it acts as an essential protective factor to prevent young people from developing an addiction, so they keep free of smartphone addiction. It is better than users are selective when buying apps that are useful for them instead of compulsively downloading many apps that take up space on their smartphone and are not used after installation. Managers can address families as influencers to promote good use and shopping habits with the smartphone using communication campaigns. Green users do not use the smartphone so much. Thus, they are fewer potential smartphone shoppers. Following Mrad and Chi Cui (2020), the prevailing negative connotation of addictive consumption poses a constant challenge to firms' efforts to promote products without risking marketing ethics problems that undermine consumers' quality of life.

On the opposite side, the red users should be provided with or should look for leisure activities (i.e. sports, walks, reading books, face-to-face talks) to address boredom proneness and avoid compulsive apps' downloading with their smartphones. Managers could promote that these users buy these products offline. Moreover, phubbing should be socially condemned as the social group can play an essential role in individual behaviour. With this problematic group, the family should establish communication norms, and the smartphone must not be involved to construe a good and healthy family harmony and maybe practice parental mediation. They are a big group of young people with bad smartphone use habits that should be tackled urgently to avoid growing up with those habits that worsened during the COVID-19 crisis. Although they buy a lot, they buy compulsively, and this is bad in the long run as it can derive in dissatisfaction and not making practical use of their smartphone. As Sundstrom et al. (2019) affirm, retailers should choose a strategy based on customer value and satisfaction, as boredom can derive in price competition and instead satisfy customers by providing an opportunity to become less bored. In this line of thought, and as Bozaci (2020) states, there is a need to manage boredom, which is one of the most important problems facing people today, as it is one of the triggering variables for smartphone addiction and impulse buying. As he suggests, people should be educated in areas appropriate to their abilities and interests so that they can comprehend the meaning of their behaviours or tasks and focus more on their activities to reduce their problematic use of smartphones and increase their ability to make more conscious fulfilling purchases. Parents and educational institutions, managers and employees can take precautions in reducing boredom. Policymakers should promote healthy smartphone use using campaigns as long as they download apps; this can be the means to address them, for example, developing educational apps that show how to use the smartphone properly. 


\section{EJMBE}

Lastly, at risk of addiction, yellow users can also benefit from leisure alternative activities, reinforcing family bonds and avoid being addict users in the future. Therefore, they should avoid boredom as it leads to addiction and search for other activities such as sports or cultural activities. Moreover, as Kleinschafer and Morrison (2014) propose, household members should establish norms to socialize among them to the intergenerational transmission of desirable behaviours.

Anyway, several of the described strategies can be used differently to help the three groups face a real/potential smartphone addiction, i.e. schools can promote talks with experts, teachers, parents and youngsters to speak about smartphone risks and healthy uses. Institutions can offer training courses regarding correct smartphone use for users of different ages, education level and home situations. Apart from the family and school, smartphone content and app developers should reflect on the need to offer not only entertaining contents but also useful tools to avoid useless downloads. In addition, they could design apps that help to foment a correct use of smartphones and provide practical cues to self-regulate smartphone use time and applications (i.e. to address youth addiction to smartphones, a game app could be developed where the avatar gets tired after a certain time playing is better than forbidding the smartphone as a punishment). As other authors have suggested (Camoiras-Rodriguez and Varela, 2020), mobile retailers need to conduct market segmentation when trying to increase their customer base and choose their potential customers according to their personalities, but also to their device use and profile.

Table 6 reflects a sum up of the main social and managerial challenges deriving from the variables used in this study to characterize clusters.

Nevertheless, further research is needed since certain limitations of this study must be recognized. The present study considers a specific demographic group (i.e. young people), it would be interesting to replicate the study with a larger sample, with adolescents, older adults or parents. In addition, the platform (prolific) employed may be conditioning the sample since people enrolled in this kind of webs might have a specific profile that may not represent the whole population. Thus, future studies should consider new demographic profiles, but other

\begin{tabular}{ll}
$\begin{array}{l}\text { Risk or } \\
\text { protective factor }\end{array}$ & Main social challenge \\
\hline $\begin{array}{l}\text { Compulsive } \\
\text { downloading }\end{array}$ & $\begin{array}{l}\text { To design entertaining apps that are } \\
\text { socially responsible and do not contribute } \\
\text { to spending much daily time in youth's life }\end{array}$
\end{tabular}

Boredom

Phubbing

Table 6.

Social and managerial challenges deriving from risk and protective factors
Main managerial challenge

The roles of marketers nowadays should focus not only on making profits over the short-term but also on offering healthy, responsible, and ethical products and services (i.e. apps, contents) for individuals, improving their quality of life and benefiting society

The managers need to be capable of detecting points to manage boredom proneness as it leads to impulse buying and not satisfactory shopping

Marketers should be aware of new social dynamics that affect how individuals interact with others and may affect their relationships with others (including brands, salesman and business) Influencers and family networks could be employed to counsel that people learn good/practical smartphone use habits (including shopping, recommending, etc.) 
ways to collect the information would be recommended (i.e. face-to-face). This study follows a cross-sectional design and the exclusive consideration of a single country (Spain); those are methodological shortcomings that restrict the generalization of the results. Future studies could study cross-national samples or collect longitudinal data. This study has focused on the individual and microsystem levels, but in the future other variables referring to the exosystem and macrosystem levels should be included in the smartphone user characterization, additional risk and protective factors, for example, perceived social support and social capital. Finally, future studies could develop a causal model to know how these risk and protective factors and addiction can precisely affect shopping.

\section{References}

Altintas, M.H., Gursakal, N., Kaufmann, H.R., Vrontis, D. and Isin, F.B. (2010), "Always-on mobile phone behaviour impulsive and postmodern consumers", International Journal of Technology Marketing, Vol. 5 No. 4, pp. 328-344, doi: 10.1504/IJTMKT.2010.039735.

Al-Saggaf, Y. and O’Donnell, S.B. (2019), "Phubbing: perceptions, reasons behind, predictors, and impacts", Human Behavior and Emerging Technologies, Vol. 1 No. 2, pp. 132-140, doi: 10.1002/ hbe2.137.

Bagozzi, R.P. and Yi, Y. (2012), "Specification, evaluation, and interpretation of structural equation models", Journal of The Academy of Marketing Science, Vol. 40 No. 1, pp. 8-34, doi: 10.1007/ s11747-011-0278-x.

Billieux, J., Van der Linden, M. and Rochat, L. (2008), "The role of impulsivity in actual and problematic use of the mobile phone", Applied Cognitive Psychology, Vol. 22 No. 9, pp. 1195-1210, doi: $10.1002 /$ acp.1429.

Bozaci (2020), "The effect of boredom proneness on smartphone addiction and impulse purchasing: a field study with young consumers in Turkey", The Journal of Asian Finance, Economics and Business, Vol. 7 No. 7, pp. 509-517, doi: 10.13106/jafeb.2020.vol7.no7.509.

Bronfenbrenner, U. (2002), "Ecological systems theory", in Vasta, R. (Ed.), Six Theories of Child Development: Revisited Formulations and Current Issues, Jessica Kingsley Publishers, London, pp. 221-288.

Buctot, D.B., Kim, N. and Kim, J.J. (2020), "Factors associated with smartphone addiction prevalence and its predictive capacity for health-related quality of life among Filipino adolescents", Children and Youth Services Review, Vol. 110, 104758, doi: 10.1016/j.childyouth.2020.104758.

Busch, P.A. and McCarthy, S. (2021), "Antecedents and consequences of problematic smartphone use: a systematic literature review of an emerging research area", Computers in Human Behavior, Vol. 114, 106414, doi: 10.1016/j.chb.2020.106414.

Camoiras-Rodriguez, Z. and Varela, C. (2020), "The influence of consumer personality traits on mobile shopping intention”, Spanish Journal of Marketing - ESIC, Vol. 24 No. 3, pp. 331-353, doi: 10. 1108/SJME-02-2020-0029.

Choi, S.W., Kim, D.J., Choi, J.S., Ahn, H., Choi, E.J., Song, W.Y., Kim, S. and Youn, H. (2015), "Comparison of risk and protective factors associated with smartphone addiction and Internet addiction", Journal of Behavioral Addictions, Vol. 4 No. 4, pp. 308-314, doi: 10.1556/2006.4.2015.043.

Chotpitayasunondh, V. and Douglas, K.M. (2016), "How 'phubbing' becomes the norm: the antecedents and consequences of snubbing via smartphone", Computers in Human Behavior, Vol. 63, pp. 9-18, doi: 10.1016/j.chb.2016.05.018.

Clayton, R.R., Leukefeld, C.G., Donohew, L., Bardo, M. and Harrington, N.G. (1995), "Risk and protective factors: a brief review", Drugs and Society, Vol. 8 Nos 3-4, pp. 7-14, doi: 10.1300/ J023v08n03_02.

David, M.E. and Roberts, J.A. (2017), "Phubbed and alone: phone snubbing, social exclusion, and attachment to social media", Journal of the Association for Consumer Research, Vol. 2 No. 2, pp. 155-163, doi: 10.1086/690940. 
De-Sola, J., Rubio, G., Talledo, H., Pistoni, L., Van Riesen, H. and de Fonseca, F.R. (2019), "Cell phone use habits among the Spanish population: contribution of applications to problematic use", Frontiers in Psychiatry, Vol. 10, pp. 1-13, doi: 10.3389/fpsyt.2019.00883.

Dinc, M. (2015), “Technology dependence and youth”, Journal of Youth Studies, Vol. 3 No. 3, pp. 31-65.

Ditrendia (2019), "Informe ditrendia: mobile en España y en el Mundo 2019", available at: https:// ditrendia.es/informes/ (accessed 10 August 2020).

Ekşi, F., Demirci, İ. and Tanyeri, H. (2020), "Problematic technology use and well-being in adolescence: the personal and relational effects of technology", The Turkish Journal on Addictions, Vol. 7, pp. 107-121, doi: 10.5152/ADDICTA.2020.19077.

Elhai, J.D., Levine, J.C., Dvorak, R.D. and Hall, B.J. (2016), "Fear of missing out, need for touch, anxiety and depression are related to problematic smartphone use", Computers in Human Behavior, Vol. 63, pp. 509-516, doi: 10.1016/j.chb.2016.05.079.

Essiz, O. and Mandrik, C. (2021), "Intergenerational influence on sustainable consumer attitudes and behaviors: roles of family communication and peer influence in environmental consumer socialization", Psychology and Marketing, in press. doi: 10.1002/mar.21540.

Farrell, A.M. (2010), "Insufficient discriminant validity: a comment on Bove, Pervan, Beatty, and Shiu (2009)", Journal of Business Research, Vol. 63 No. 3, pp. 324-327, doi: 10.1016/j.jbusres.2009. 05.003.

Fereday, J. and Muir-Cochrane, E. (2006), "Demonstrating rigor using thematic analysis: a hybrid approach of inductive and deductive coding and theme development", International Journal of Qualitative Methods, Vol. 5 No. 1, pp. 80-92, doi: 10.1177/ 160940690600500107.

Franchina, V., Vanden Abeele, M., Van Rooij, A.J., Lo Coco, G. and De Marez, L. (2018), "Fear of missing out as a predictor of problematic social media use and phubbing behavior among Flemish adolescents", International Journal of Environmental Research and Public Health, Vol. 15 No. 10, p. 2319, doi: 10.3390/ijerph15102319.

Fuller, C.M., Simmering, M.J., Atinc, G., Atinc, Y. and Babin, B.J. (2016), "Common methods variance detection in business research", Journal of Business Research, Vol. 69 No. 8, pp. 3192-3198, doi: 10.1016/j.jbusres.2015.12.008.

Gökçearslan, Ş., Uluyol, Ç. and Şahin, S. (2018), "Smartphone addiction, cyberloafing, stress and social support among university students: a path analysis", Children and Youth Services Review, Vol. 91, pp. 47-54, doi: 10.1016/j.childyouth.2018.05.036.

Hall-Newton, K., Rudkowski, J., Mark, H.L.S., Hogue, J. and Ratnichkina, P. (2019), "Mobile devices in the lecture hall: into it, indifferent, or intrusion?", Journal of Education for Business, Vol. 94 No. 6, pp. 390-399, doi: 10.1080/08832323.2018.1541853.

Handa, M. and Ahuja, P. (2020), "Disconnect to detox: a study of smartphone addiction among young adults in India”, Young Consumers, Vol. 21 No. 3, pp. 273-287, doi: 10.1108/YC-12-2019-1077.

Hong, J.S. and Garbarino, J. (2012), "Risk and protective factors for homophobic bullying in schools: an application of the social-ecological framework", Educational Psychology Review, Vol. 24 No. 2, pp. 271-285, doi: 10.1007/s10648-012-9194-y.

Hsiao, K.L. (2017), "Compulsive mobile application usage and technostress: the role of personality traits", Online Information Review, Vol. 41 No. 2, pp. 272-295, doi: 10.1108/OIR-03-2016-0091.

Jeong, J.Y., Suh, B. and Gweon, G. (2020), "Is smartphone addiction different from Internet addiction? comparison of addiction-risk factors among adolescents", Behaviour and Information Technology, Vol. 39 No. 5, pp. 578-593, doi: 10.1080/0144929X.2019.1604805.

Jessor, R. (1992), "Risk behavior in adolescence: a psychosocial framework for understanding and action”, Developmental Review, Vol. 12 No. 4, pp. 374-390, doi: 10.1016/0273-2297(92)90014-S.

Kavikondala, S., Stewart, S.M., Ni, M.Y., Chan, B.H., Lee, P.H., Li, K.K., McDowell, I., Johnston, J.M., Chan, S.S., Lam, T.H., Lam, W.W. and Fielding, R. (2016), "Structure and validity of Family 
Harmony Scale: an instrument for measuring harmony", Psychological Assessment, Vol. 28 No. 3, pp. 307-318, doi: 10.1037/pas0000131.

Kayri, M. and Günüç, S. (2016), "Comparing Internet Addiction in students with high and low socioeconomic status levels", Addicta: The Turkish Journal on Addiction, Vol. 3, pp. 177-183, doi: 10.15805/addicta.2016.3.0110.

Kim, H.J., Min, J.Y., Min, K.B., Lee, T.J. and Yoo, S. (2018), "Relationship among family environment, self-control, friendship quality, and adolescents' smartphone addiction in South Korea: findings from nationwide data”, PloS One, Vol. 13 No. 2, pp. 1-13, doi: 10.1371/ journal.pone.0190896.

Kiss, H., Fitzpatrick, K.M. and Piko, B.F. (2020), "The digital divide: risk and protective factors and the differences in problematic use of digital devices among Hungarian youth", Children and Youth Services Review, Vol. 108, 104612, doi: 10.1016/j.childyouth.2019.104612.

Kleinschager, J. and Morrison, M. (2014), "Household norms and their role in reducing household electricity consumption”, International Journal of Consumer Studies, Vol. 38 No. 1, pp. 75-81, doi: 10.1111/ijcs.12066.

Kodinariya, T.M. and Makwana, P.R. (2013), "Review on determining number of cluster in K-means clustering", International Journal, Vol. 1 No. 6, pp. 90-95.

Krzanowski, W.J. and Lai, Y.T. (1988), "A criterion for determining the number of groups in a data set using sum-of-squares clustering”, Biometrics, Vol. 44 No. 1, pp. 23-34, doi: 10.2307/2531893.

Kwak, J.Y., Kim, J.Y. and Yoon, Y.W. (2018), "Effect of parental neglect on smartphone addiction in adolescents in South Korea", Child Abuse and Neglect, Vol. 77, pp. 75-84, doi: 10.1016/j.chiabu. 2017.12.008.

Kwon, M., Kim, D.J., Cho, H. and Yang, S. (2013), "The smartphone addiction scale: development and validation of a short version for adolescents", PloS One, Vol. 8 No. 12, pp. 1-7, doi: 10.1371/ journal.pone.0083558.

Kwon, T.A., Choo, H.J. and Kim, Y.-K. (2020), "Why do we feel bored with our clothing and where does it end up?", International Journal of Consumer Studies, Vol. 44 No. 1, pp. 1-13, doi: 10.1111/ ijcs.12540.

Lee, C. and Lee, S.J. (2017), "Prevalence and predictors of smartphone addiction proneness among Korean adolescents", Children and Youth Services Review, Vol. 77, pp. 10-17, doi: 10.1016/j. childyouth.2017.04.002.

Leung, L. (2007), "Leisure boredom, sensation seeking, self-esteem, addiction symptoms and patterns of mobile phone use", E.K., M.T., S.U. and A.L. (Eds), Mediated Interpersonal Communication, Lawrence Erlbaum Associates, Mahwah, New Jersey, NJ, pp. 1-36.

Lian, L. and You, X. (2017), "Specific virtues as predictors of smartphone addiction among Chinese undergraduates", Current Psychology, Vol. 36 No. 2, pp. 376-384, doi: 10.1007/s12144-017-9612-x.

Liu, Q., Sun, J., Li, Q. and Zhou, Z. (2020a), "Body dissatisfaction and smartphone addiction among Chinese adolescents: a moderated mediation model", Children and Youth Services Review, Vol. 108, 104613, doi: 10.1016/j.childyouth.2019.104613.

Liu, Q.Q., Yang, X.J., Hu, Y.T., Zhang, C.Y. and Nie, Y.G. (2020b), "How and when is family dysfunction associated with adolescent mobile phone addiction? Testing a moderated mediation model", Children and Youth Services Review, Vol. 111, 104827, doi: 10.1016/j. childyouth.2020.104827.

López-Fernández, O. (2017), "Short version of the Smartphone Addiction Scale adapted to Spanish and French: towards a cross-cultural research in problematic mobile phone use", Addictive Behaviors, Vol. 64, pp. 275-280, doi: 10.1016/j.addbeh.2015.11.013.

Mahapatra, S. (2019), "Smartphone addiction and associated consequences: role of loneliness and selfregulation", Behaviour and Information Technology, Vol. 38 No. 8, pp. 833-844, doi: 10.1080/ 0144929X.2018.1560499. 
Malhotra, N.K., Kim, S.S. and Patil, A. (2006), "Common method variance in IS research: a comparison of alternative approaches and a reanalysis of past research", Management Science, Vol. 52 No. 12, pp. 1865-1883, doi: 10.1287/mnsc.1060.0597.

Milijic, M. (2019), "29+ smartphone usage statistics: around the world in 2020", available at: https:// leftronic.com/smartphone-usage-statistics/ (accessed 29 December 2020).

Miller-Ott, A.E. and Kelly, L. (2017), "A politeness theory analysis of cellphone usage in the presence of friends”, Communication Studies, Vol. 68 No. 2, pp. 190-207, doi: 10.1080/10510974.2017. 1299024.

Mrad, M. and Chi Cui, C. (2020), "Comorbidity of compulsive buying and brand addiction: an examination of two types of addictive consumption", Journal of Business Research, Vol. 113, pp. 399-408, doi: 10.1016/j.jbusres.2019.09.023.

Noë, B., Turner, L.D., Linden, D.E., Allen, S.M., Winkens, B. and Whitaker, R.M. (2019), "Identifying indicators of smartphone addiction through user-app interaction", Computers in Human Behavior, Vol. 99, pp. 56-65, doi: 10.1016/j.chb.2019.04.023.

O'Connell, M.E., Boat, T. and Warner, K.E. (2009), Preventing Mental, Emotional, and Behavioral Disorders Among Young People: Progress and Possibilities, The National Academies Press, Washington, DC.

Okazaki, S., Schuberth, F., Tagashira, T. and Andrade, V. (2019), "Sneaking the dark side of brand engagement into Instagram: the dual theory of passion", Journal of Business Research, Vol. 130, pp. 493-505, doi: 10.1016/j.jbusres.2019.11.028.

Pallant, J. (2001), SPSS Survival Manual, Buckingham Open University Press, Maidenhead.

Parylak, S.L., Koob, G.F. and Zorrilla, E.P. (2011), "The dark side of food addiction”, Physiology and Behavior, Vol. 104 No. 1, pp. 149-156, doi: 10.1016/j.physbeh.2011.04.063.

Pourrazavi, S., Allahverdipour, H., Jafarabadi, M.A. and Matlabi, H. (2014), "A sociocognitive inquirí of excessive mobile phone use”, Asian Journal of Psychiatry, Vol. 10, pp. 84-89, doi: 10.1016/j.ajp. 2014.02.009.

Punj, G. and Stewart, D.W. (1983), "Cluster analysis in marketing research: review and suggestions for application”, Journal of Marketing Research, Vol. 20 No. 2, pp. 134-148, doi: $10.2307 / 3151680$.

Rastreator (2019), "Crece la adicción al móvil entre los jóvenes: el 45\% ya se considera adicto", available at: https://www.rastreator.com/sala-de-prensa/notas-de-prensa/2017-08-crece-adiccionmovil-entre-jovenes.aspx (accessed 29 December 2020).

Regan, T., Harris, B., Van Loon, M., Nanavaty, N., Schueler, J., Engler, S. and Fields, S.A. (2020), “Does mindfulness reduce the effects of risk factors for problematic smartphone use? Comparing frequency of use versus self-reported addiction”, Addictive Behaviors, Vol. 108, 106435, doi: 10. 1016/j.addbeh.2020.106435.

Rita, P., Ramos, R.F., Moro, S., Mealha, M. and Radu, L. (2021), "Online dating apps as a marketing channel: a generational approach", European Journal of Management and Business Economics, Vol. 30 No. 1, pp. 1-17, doi: 10.1108/EJMBE-10-2019-0192.

Roberts, J.A., Pullig, C. and Manolis, C. (2015), "I need my smartphone: a hierarchical model of personality and cell-phone addiction”, Personality and Individual Differences, Vol. 79, pp. 13-19, doi: 10.1016/j.paid.2015.01.049.

Rook, D.W. and Fisher, R.J. (1995), "Normative influences on impulsive buying behavior", The Journal of Consumer Research, Vol. 22, pp. 305-313, doi: 10.1086/209452.

Scholderer, J. and Grunert, K.G. (2001), "Does generic advertising work? A systematic evaluation of the Danish campaign for fresh fish", Aquaculture Economics and Management, Vol. 5 Nos 5-6, pp. 253-271, doi: 10.1080/13657300109380293.

Sensortower (2020), "Global app revenue reached $\$ 50$ billion in the first half of 2020, up 23\% yearover-year", available at: https://sensortower.com/blog/app-revenue-and-downloads-1h-2020 (accessed 29 December 2020). 
Seo, M., Kim, J.H. and David, P. (2015), “Always connected or always distracted? ADHD symptoms and social assurance explain problematic use of mobile phone and multicommunicating", Journal of Computer-Mediated Communication, Vol. 20 No. 6, pp. 667-681, doi: 10.1111/jcc4.12140.

Sha, P., Sariyska, R., Riedl, R., Lachmann, B. and Montag, C. (2019), "Linking Internet communication and smartphone use disorder by taking a closer look at the Facebook and WhatsApp applications", Addictive Behaviors Reports, Vol. 9, pp. 1-9, doi: 10.1016/j.abrep.2018.100148.

Shu, C.Y. and Chieh-Ju, T. (2007), "Comparison of Internet addicts and non-addicts in Taiwanese high school”, Computers in Human Behavior, Vol. 23 No. 1, pp. 79-96, doi: 10.1016/j.chb.2004.03.037.

Smartme Analytics (2020), "Impacto uso del smartphone crisis del coronavirus", available at: https:// dub01.online.tableau.com/\#/site/smartmeanalytics/views/CrisisCOVID19_Dashboard/ CrisisCOVID19_Dashboard?:iid=2 (accessed 29 December 2020).

Statista (2020), "Number of smartphone users worldwide from 2016 to 2021", available at: https:// www.statista.com/statistics/330695/number-of-smartphone-users-worldwide/ (accessed 29 December 2020).

Sundström, M., Hjelm-Lidholm, S. and Radon, A. (2019), "Clicking the boredom away - exploring impulse fashion buying behavior online", Journal of Retailing and Consumer Services, Vol. 47, pp. 150-156, doi: 10.1016/j.jretconser.2018.11.006.

Tang, J., Zhang, B. and Akram, U. (2019), "User willingness to purchase applications on mobile intelligent devices: evidence from app store”, Asia Pacific Journal of Marketing and Logistics, Vol. 32 No. 8, pp. 1629-1649, doi: 10.1108/APJML-06-2019-0411.

Turner (2020), "How many smartphones are in the world?", available at: https://www.bankmycell.com/ blog/how-many-phones-are-in-the-world (accessed 29 December 2020).

Vaghefi, I. and Lapointe, L. (2016), “A typology of user liability to IT addiction”, Information Systems Journal, Vol. 27 No. 2, doi: 10.1111/isj.12098.

Wolniewicz, C.A., Rozgonjuk, D. and Elhai, J.D. (2020), "Boredom proneness and fear of missing out mediate relations between depression and anxiety with problematic smartphone use", Human Behavior and Emerging Technologies, Vol. 2 No. 1, pp. 61-70, doi: 10.1002/hbe2.159.

Xie, X., Chen, W., Zhu, X. and He, D. (2019), "Parents' phubbing increases Adolescents' Mobile phone addiction: roles of parent-child attachment, deviant peers, and gender", Children and Youth Services Review, Vol. 105, 104426, doi: 10.1016/j.childyouth.2019.104426.

Yang, Z., Asbury, K. and Griffiths, M.D. (2019), "An exploration of problematic smartphone use among Chinese university students: associations with academic anxiety, academic procrastination, self-regulation and Subjective wellbeing", International Journal of Mental Health and Addiction, Vol. 17 No. 3, pp. 596-614, doi: 10.1007/s11469-018-9961-1.

Yen, J.Y., Yen, C.F., Chen, C.C., Chen, S.H. and Ko, C.H. (2007), "Family factors of Internet addiction and substance use experience in Taiwanese adolescents", CyberPsychology and Behavior, Vol. 10 No. 3, pp. 323-329, doi: 10.1089/cpb.2006.9948.

Yen, C.H., Tang, T.C., Yen, J.Y., Lin, H.C., Huang, C.F., Liu, S.C. and Ho, C.H. (2009), "Symptoms of problematic cellular phone use, functional impairment and its association with depression among adolescents in Southern Taiwan”, Journal of Adolescence, Vol. 32, pp. 863-873, doi: 10. 1016/j.adolescence.2008.10.006.

\section{Corresponding author}

Sonia San-Martín can be contacted at: sanmargu@ubu.es

For instructions on how to order reprints of this article, please visit our website:

www.emeraldgrouppublishing.com/licensing/reprints.htm

Or contact us for further details: permissions@emeraldinsight.com 